\title{
Manajemen Anestesi pada bayi prematur dengan asosiasi VACTERL
}

\section{Anesthetic management on a premature neonate with VACTERL association}

PrimartantoWibowo \*, Corry QuandoYahya**

* Bagian Anestesi dan terapi intensif RS Siloam Lippo Village, Tangerang

** Fakultas Kedokteran Universitas Pelita Harapan, Tangerang

$\bowtie$ Korespondensi/Correspondence: prima_wibowo@yahoo.com

\section{ABSTRACT}

Background: VACTREL syndrome is a congenital disorder involving vertebral malformations, anal atresia, cardiovascular anomalies, kidney malformations and structural abnormalities of the limbs. Anesthetic management in such patients carries a high risk of mortality due to cardiac and renal anomalies that may affect the hemodynamic status.

Case : Presented an anesthetic management of a preterm male infant at 28 weeks gestation, weighing 1,795gr who underwent colonostomy due to anal atresia. Heart rate 157x/minute, Respiratory rate 40x/minute, there were crackles on both lung and systolic murmur. Patient's oxygen saturation 98\% using nasal continuous positive airway pressure (NCPAP) oxygen inspiration fraction 40\%. Induction using 0,2 $\mathrm{mg}$ midazolam, $2 \mathrm{mg}$ ketamin, $2 \mathrm{mcg}$ Fentanyl ${ }^{R}$. Rapid sequence intubation with $100 \%$ oxygen ventilation using Jackson-Rees circuit respiratory rate 50-60x /minute. Anesthetic maintenance using oxygen 100\% $4 \mathrm{~L} /$ minute and 1 volume percent isoflurane. After the use of isoflurane, patients experienced desaturation up to $92 \%$ and bradycardia up to $125 \mathrm{x} /$ minute. Isoflurane discontinued replaced with ketamine. After hemodynamically stable, the incision begins. During the surgical procedure, the heart rate range at 125-155 x/ minute with 98-100\% oxygen saturation. Duration of operation was 95 minutes. Post surgery treated in the NICU. The patient died on day 12 post-operative care in the NICU

Summary: The management of anesthesia in patients VACTERL mainly focused on existing cardiovascular abnormalitiesand also the balance between the SVR and PVR.

Keywords: anesthetic management, infant, VACTERL

\begin{abstract}
ABSTRAK
Latar Belakang: Sindrom VACTERL merupakan kelainan kongenital yang melibatkan malformasi vertebra, atresia anal, anomali kardiovaskular, malformasi ginjal dan kelainan struktur pada tungkai. Manajemen anestesi pada pasien tersebut memiliki risiko mortalitas tinggi karena adanya anomali jantung dan ginjal yang dapat mempengaruhi status hemodinamik.
\end{abstract}

Kasus :Dilaporkan penanganan anestesi pada bayi prematur berusia 28 minggu berat 
1,795gr menjalani operasi kolonostomi atresia ani. Frekuensi nadi 157x/menit, frekuensi napas 40x/menit, terdapat ronki pada kedua lapang paru dan murmur sistolik. Saturasi oksigen pasien 98\% menggunakan nasal continuous positive airway pressure (NCPAP) fraksi inspirasi oksigen 40\%.Induksi menggunakan 0,2 mg midazolam, $2 \mathrm{mg}$ ketamin, $2 \mathrm{mcg}$ Fentanyl $^{R}$. Rapid sequence intubation diberikan ventilasi dengan oksigen 100\% menggunakan sirkuit Jackson-Rees frekuensi pernapasan 50-60 kali/menit. Rumatan anestesi dilakukan menggunakan oksigen 100\% 4 liter per menit dan 1 volume percent isofluran. Setelah penggunaan isofluran, pasien mengalami desaturasi hingga 92\% dan bradikardia hingga 125 kali per menit. Isofluran dihentikan diganti denganketamin. Setelah hemodinamik stabil, insisi dimulai. Selama prosedur operasi, denyut jantung berkisar di 125-155 kali per menit dengan saturasi oksigen 98-100\%. Lama operasi 95 menit. Post operasi dirawat di NICU. Pasien meninggal pada hari ke-12 perawatan pasca operasi di NICU.

Ringkasan: Tata laksana anestesi pada pasien VACTERL terutama di fokuskan pada kelainan kardiovaskuler yang ada dengan memperhatikan keseimbangan antara SVR dan PVR.

Kata Kunci: bayi, manajemen anestesi, VACTERL

\section{PENDAHULUAN}

Insiden kelahiran dengan kelainan kongenital multipel sangat jarang terjadi, salah satunya adalah VACTERL yang meliputi anomali Vertebra, atresia Ani, defek Kardiak, fistula trakeoEsofageal, anomali ginjal, dan defek ekstremitas. Insiden VACTERL diperkirakan mencapai 1 tiap 40,000 kelahiran hidup. ${ }^{1,2}$

Adanya defek yang mengenai banyak sistem organ memerlukan penanganan anestesia secara khusus dalam prosedur operasi yang dijalankan pada kasus VACTERL. Dalam laporan kasus ini, penulis ingin membagikan penanganan anestesia pada kasus neonatus berat badan lahir rendah dengan VACTERL yang menjalani operasi kolostomi darurat.

\section{KASUS}

Seorang bayi laki-laki 1,795 gram dilahirkan dengan operasi caesar akibat gawat janin. Pada pemeriksaan didapatkan sumbing bibir dan langit-langit mulut, atresia ani, talipes equinovarus, defek septum ventrikel dengan diameter $5 \mathrm{~mm}$, patent ductus arteriosus, dilatasi arteri pulmonalis dan dugaan adanya meningoencephalokel, sehingga dipikirkan bahwa kasus terkait dengan VACTERL (Gambar 1).

Gambar 1. Hasil ekokardiografi yang menunjukkan defek septum ventrikel seluas $5 \mathrm{~mm}$.

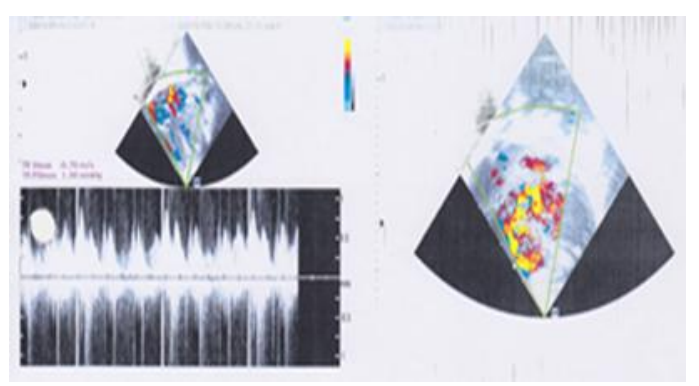

Dari pemeriksaan penunjang laboratorium didapatkan $\mathrm{Hb}: 15.0 \mathrm{~g} / \mathrm{dL}$, Hct : 45,7\%, 
leukosit: 12270, trombosit : 101000, elektrolit dalam batas normal, partial tromboplastin time 14,80 (kontrol : 9,8-12,60), activated partial thromboplastin time : 75,5 detik (kontrol 31 - 47). Pasien direncanakan operasi kolostomi darurat. Dalam persiapan operasi di neonatus intensive care unit (NICU), dilakukan pemasangan pipa nasogastrik dan diberikan air susu ibu sebanyak $1 \mathrm{ml}$ tiap empat jam, pasien juga mendapat tambahan Aminosterile $^{\mathrm{R}} 1 \mathrm{~g} / \mathrm{kgBB} /$ hari. Dari pemeriksaan laboratorium didapatkan pemanjangan nilai faal hemostasis dan diberikan transfusi $15 \mathrm{ml}$ plasma dan thrombocyte concentrate $90 \mathrm{ml} / \mathrm{kgBB} / \mathrm{h}$ ari.

Operasi dilakukan setelah transfusi, 48 jam pasca lahir, kondisi pasien letargi, abdomen cembung namun supel. Di kamar operasi, monitoring yang bisa dipasang pada pasien adalah 3 lead elektrokardiografi dan oksimetri. Tidak dilakukan pemantauan tekanan darah baik non invasif ataupun invasif karena alat tidak tersedia. Frekuensi nadi $157 \mathrm{x} /$ menit, frekuensi napas $40 \mathrm{x} /$ menit, terdapat ronki pada kedua lapang paru dan murmur sistolik. Saturasi oksigen pasien 98\% menggunakan nasal continuous positive airway pressure (NCPAP) dengan fraksi inspirasi oksigen $40 \%$.

Induksi menggunakan $0,2 \mathrm{mg}$ midazolam, 2 mg ketamin, 2 mcg Fentanyl ${ }^{\mathrm{R}}$. Setelah rapid sequence intubation diberikan ventilasi dengan oksigen 100\% menggunakan sirkuit Jackson-Rees dengan frekuensi pernapasan 50-60 kali/menit. Kemudian rumatan anestesi dilakukan menggunakan oksigen $100 \% 4$ liter per menit dan 1 volume percent isofluran.
Setelah penggunaan isofluran, pasien mengalami desaturasi sampai dengan 92\% dan bradikardia sampai dengan 125 kali per menit. Isofluran dihentikan dan diputuskan rumatan anestesi menggunakan ketamin. Setelah hemodinamik stabil, insisi dimulai. Selama prosedur operasi, denyut jantung pasien berkisar di 125-155 kali per menit dengan saturasi oksigen $98-100 \%$. Prosedur operasi berlangsung selama 95 menit, kemudian pasien ditransfer ke NICU dengan terintubasi dan tersedasi. Pasien meninggal pada hari ke-12 perawatan pasca operasi di NICU.

\section{PEMBAHASAN}

Penanganan anestesi pada neonatus dengan VACTERL mempunyai tantangan unik tersendiri. Adanya sumbing bibir dan langit-langit mulut akan menambah tantangan dalam penanganan jalan napas pada pasien ini yang nantinya akan mempengaruhi kelainan mayor yang ada pada pasien ini.

Adanya defek sekat ventrikel yang besar akan meningkatkan aliran darah ke arteri pulmonalis sepanjang tekanan ventrikel kiri lebih besar daripada tekanan di ventrikel kanan. Namun peningkatan aliran ini akan diikuti oleh peningkatan tekanan di arteri pulmonalis sehingga nanti akan terjadi overvolume di ventrikel kanan yang akan meningkatkan tekanan ventrikel kanan (Gambar 2).

Bila tekanan ventrikel kanan meningkat, maka kondisi yang tadinya pirau kiri ke kanan akan menjadi pirau kanan ke kiri, sehingga pasien akan menjadi lebih 


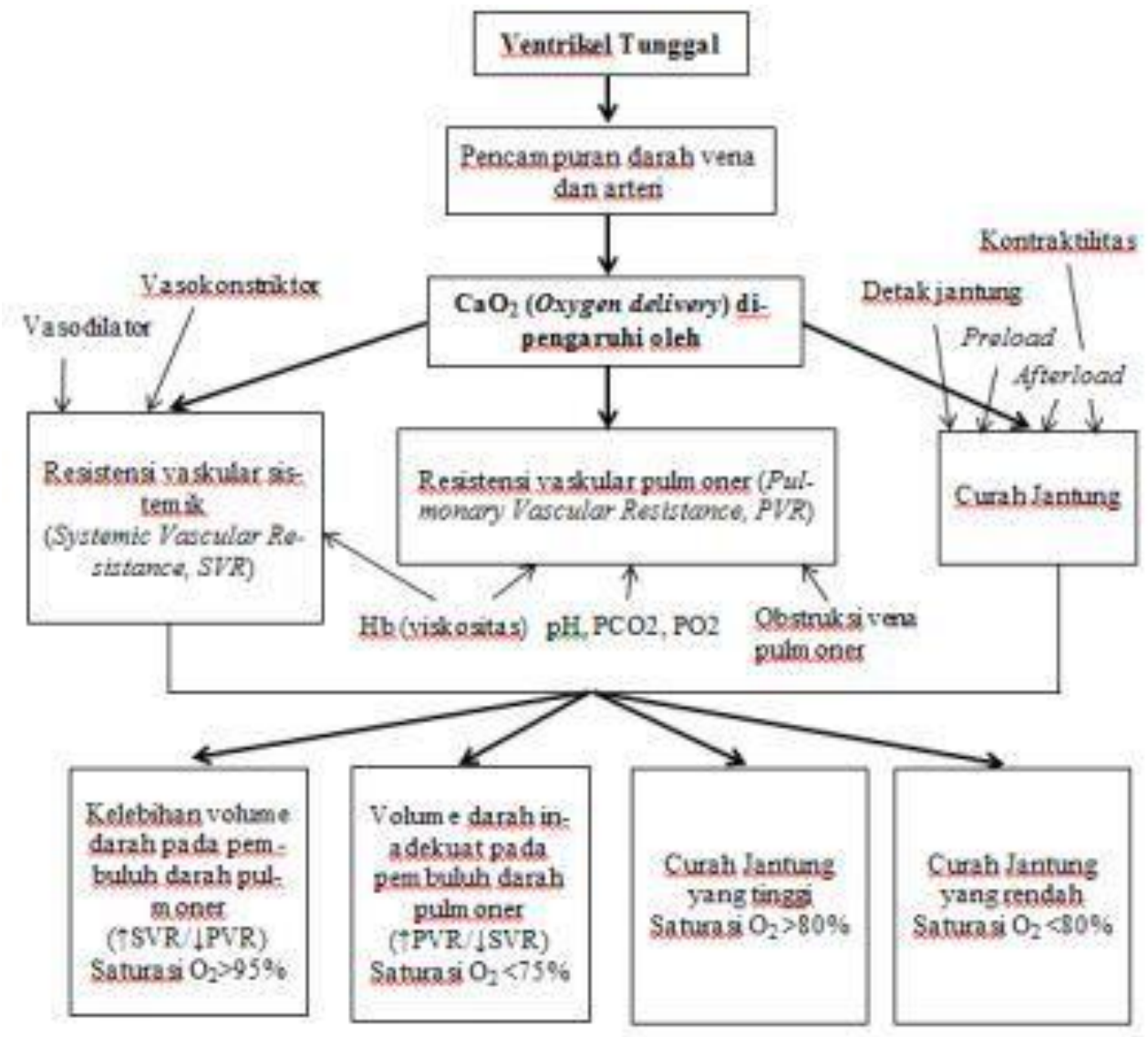

Gambar 2.Hubungan antara SVR dan PVR

hipoksemia dibandingkan saat sebelumnya. Sehingga fokus penanganan pasien ini adalah pencegahan terjadinya pirau kanan ke kiri. $^{3}$

Pencegahan pirau kanan ke kiri ini bisa dilakukan dengan cara menyeimbangkan resistensi vaskuler sistemik (systemic vascular resistancy / SVR) dengan resistensi vaskuler paru (pulmonary vascular resistancy / PVR). Kondisi yang menyebabkan peningkatan PVR harus dihindari. Kondisi tersebut antara lain : hipoksia, asidosis, nyeri. Sementara SVR harus dijaga agar tidak mengalami penurunan tiba-tiba untuk menghindari pirau kanan ke kiri yang akan menjadi sindroma Eissenmenger. ${ }^{3}$
Penanganan anestesi untuk kasus demikian dimulai dari sebelum tindakan anestesi dilaksanakan. Kecukupan oksigenasi dan kecukupan volume cairan tubuh menjadi hal yang sangat penting. Persiapan preoperatif tersebut diharapkan terpenuhi dengan perawatan pasien di NICU. Karena sifat operasi yang mendesak, maka pemilihan jenis dan obat anestesi menjadi sangat penting. Untuk itu, dipilih suatu tindakan "balance anesthesia" dengan menggunakan obat anestesi yang dapat menjaga kestabilan antara oksigenasi, SVR dan PVR.

Nyeri operasi merupakan bentuk stres yang akan menstimulasi pelepasan katekolamin yang akan mempengaruhi oksigenasi, SVR dan PVR. ${ }^{4}$ Untuk itu, pe- 
nanganan nyeri yang baik akan melancarkan jalannya prosedur operasi sehingga midazolam dan fentanyl dipilih sebagai obat ko induksi dan ketamin sebagai obat induksi. Efek depresi dari midazolam dan fentanyl dicoba diimbangkan dengan pemberian ketamin sebagai obat induksi, diharapkan dapat meningkatkan potensi analgetik dan memudahkan intubasi. ${ }^{5,6}$ Namun saat digunakan isofluran sebagai rumatan, terjadi penurunan denyut jantung dan desaturasi. Desaturasi pasca isofluran diperkirakan terjadi akibat inhibisi mobilisasi kalium dan peningkatan sensitivitas myofilamen otot polos pembuluh darah sehingga terjadi vasodilatasi. Penurunan SVR ini yang disertai adanya PVR yang (memang sudah) tinggi akan menyebabkan peningkatan aliran darah dari ventrikel kanan ke kiri sehingga darah yang tidak teroksigenasi lah yang disirkulasikan ke aorta dan menyebabkan desaturasi. Desaturasi yang berkelanjutan akan meningkatkan PVR dan meningkatkan tekanan ventrikel kanan untuk kemudian menjadi pirau kanan ke kiri, begitu seterusnya sampai menetap (sindroma Eissenmenger).

Saat hipoksia, jantung akan bekerja lebih cepat untuk memenuhi kebutuhan oksigenasi jaringan sebagai kompensasinya. Pada neonatus, kemampuan jantung untuk mengkompensasi hipoksemia sangat terbatas, sehingga bisa berakibat pada penurunan fungsi jantung. ${ }^{3}$ Namun bradikardia yang terjadi mungkin karena perlambatan pada nodus sinoatrial akibat pemendekan potensial aksi otot jantung dan pemanjangan durasi refrakter dari serabut Purkinje akibat pengaruh isofluran. ${ }^{7}$ Untuk menggantikan isofluran maka rumatan anestesia kemudian menggunakan ketamin intravena. Ketamin menjadi pilihan karena ketamin mempunyai efek sedasi dan analgetik serta tidak menimbulkan depresi pada sistem kardiovaskuler.

Komunikasi dengan dokter bedah menjadi hal yang sangat penting dalam tatalaksana anestesi pasien dengan VACTERL. Prosedur pembedahan sebaiknya dilakukan seminimal mungkin dan secepat mungkin untuk menghindari gangguan hemodinamik yang berkelanjutan ${ }^{8}$.

Pasca operasi, pasien dirawat di NICU dengan ventilator untuk menjamin oksigenasi pada pasien ini. Selama perawatan hemodinamik pasien tidak stabil, beberapa kali terjadi desaturasi. Pasien meninggal pada perawatan hari ke-12 pasca operasi.

\section{RINGKASAN}

Tata laksana anestesi pada pasien VACTERL terutama di fokuskan pada kelainan kardiovaskuler yang ada. Pada kasus ini, adanya VSD besar dan dilatasi arteri pulmonalis yang diduga disertai dengan peningkatan tekanan arteri pulmonalis, penanganan anestesinya harus memperhatikan keseimbangan antara SVR dan PVR. Tata laksana anestesi yang dilakukan harus berdasarkan kondisi klins pasien dan secara titrasi (tailoring). Hal ini terbukti dari penggunaan gas anestesi (isofluran) yang pada kasus lain berguna, namun pada pasien ini menimbulkan hal sebaliknya. 


\section{DAFTAR PUSTAKA}

1. Quan L, Smith D: The VATER association. Vertebral defects, anal atresia, T-E fistula with esophageal atresia, radial and renal dysplasia: a spectrum of associated defects. J Pediatr. 1973;82:104-107.

2. Solomon, BD. VACTERL/VATER Association. Orph J rare dis.2011;6:56

3. Greeley, WJ. Pediatric cardiovascular anesthesia. Anesthesia and Analgesia.1995 Suppl:45-56

4. Schmeling DJ, Coran AG. The hormonal and metabolic response to stress in neonate. J PedSurg Int. 1990;5:307-21

5. Lois F, Kock MD. Something new about ketamine for pediatric anesthesia? CurrOpinAnesthesiol. 2008;21:340-4.

6. Anand KJS, Hall RW. Pharmacological therapy for analgesia and sedation in the newborn. Arch Dis Child Fetal Neonatal Ed. 2006;91:F448-53

7. Martin DL, Dissen GA, McPike MJ, Brambrink AM. Effects of Anesthesia with Isoflurane, Ketamine or Propofol on Physiologic Parameters in Neonatal Rhesus Macaques (Macacamulatta). J Am Assoc Lab Anim Sci.2014;53:290-300

8. Rivenes SM, Lewin MB, Stayer SA, Bent ST, Schoenig HM, McKenziee ED et al. Cardiovascular effects of sevoflurane, isoflurane, halothane, and fentanylmidazolam in children with congenital heart disease: an echocardiographic study of myocardial contractility and hemodynamics. Anesthesiology. 2001; 94(2):223 -9 . 